\title{
A PROFISSIONAL ENFERMEIRA FRENTE AS INFLUENCIAS DA EVOLUÇÃO HISTÓRICA DA MULHER
}

* SÔNIA REGINA CORADINI

${ }^{*}$ ROSMARI BARBIANI

\section{INTRODUÇÃO}

A escolha deste tema se dá baseado num inconformismo com a situação social da mulher frente ao seu desempenho na sociedade. Mulher esta que há milênios foi tida como um "ser", mas que com a predominância de grupos dominadores nos caminhos da história, diversos tipos de sistemas sociais, fizeram com que estes leves indícios de ascedência fossem apagados e que ao longo dos tempos permaneceram submersos.

Partindo do pressuposto que a Enfermagem é uma profissão predominantemente feminina, a problemática atinge diretamente também a Enfermeira. Enfermeira esta, que tem um papel relevante de atuação na sociedade, que através de condicionamentos que passaram a ser comportamentos seus, em seu campo de trabalho muitas vezes, tem uma atuação, não de liderança mas de subjugação e não se impõe como profissional autônoma e liberal, anulando-se desta forma. Muitas vezes tendo uma participação muito restrita no que se refere as lutas e interesses da maior parte da população brasileira.

Consta este de um histórico da mulher até o século atual; uma análise da influência da família, estudo de etapas de influência desde o nascimento até a adolescência; a moral sexual; a libertação das mulheres; a mulher, o trabalho e a CLT; o Perfil atual da Profissional Enfermeira.

A problematização enfoca a influência da evolução histórica da mulher na profissional enfermeira, partindo de uma realidade encontrada onde vivencia-se a mesma pouco atuante, temerosa e muitas vezes submissa.

Entende-se por evolução histórica, o desenvolvimento progressivo de uma idéia, através de fatos notáveis, ocorridos na vida dos povos, em particular, e da humanidade, em geral. Profissional Enfermeira, indivíduo com o curso de Enfermagem a nível universitário, com conhecimento científico concernente ao cargo que ocupa.

Pretende este trabalho mostrar o porquê da situação atual da Enfermeira em seu campo de trabalho e extrapolar para uma justificativa de seu indevido reconhecimento como profissional.

Tem-se como objetivos gerais definir numa visão ampla, a evolução da mulher e suas implicações especificamente na profissional enfermeira. E como específicos coletar material bibliográfico que reforcem a presente proposição de comprovar as influências da evolução histórica da mulher na enfermeira, tentando a partir daí, reforçar a idéia do por que de sua diminuta atuação como indivíduo e profissional.

\section{EVOLUÇÃO HISTÓRICA DA MULHER}

"Tudo o que os homens escrevem sobre as mulheres deve ser suspeito, pois eles são, a um tempo, juiz e parte."

Paulaim de la Barre

A História mostra que o sistema familiar predominantemente é o patriarcal, que dura há aproximadamente 7 mil anos. As correntes conservadoras pretendem que ele seja eterno e determina-

\footnotetext{
* Enfermeira do Hospital da Criança Santo Antônio - POA

** Enfermeira do Hospital Dr. Bartholomeu Tachini - Bento Gonçalves.
} 
CORADINI, S.R. e colaboradora - A profissional enfermeira frente as influências da evolução histórica da mulher. Rev. Bras. Enf.: RS, 36: 246-254, 1983.

do por condições "naturais" são "modificáveis". Correntes progressistas com bases principalmente em descobertas arqueológicas dos últimos anos, defendem que existia antes do patriarcado um tipo de sociedade humana mais igualitária, com características marcantes como a inexistência de dominação de um grupo sobre o outro, ou de um indivíduo sobre o outro e a inexistência de guerra. Essas sociedades são chamadas por alguns de matriarcais.

No Império de Carlos Magno (sec. 8) as mulheres foram excluídas do corpo de funcionários, mas foi mantida a tradição de lhes assegurar a administração de seus domínios.

A repressão contra as mulheres começa a ser exercida através da operação caça as bruxas, sendo de grande destaque a Igreja, através da Inquisição que levou milhares de mulheres à morte.

No século 16, a monarquia, a Igreja e a burguesia ascendente encerram a mulher novamente no âmbito familiar, privando-a de antigas funçōes e direitos. Apesar disto algumas conseguem se destacar nas letras.

Nos dois séculos seguintes, pouca coisa mudou na condição feminina, restando às mulheres apenas dois caminhos para tentar escapar de uma identidade cultural, através do autodidatismo.

Neste tempo aconteceram fatos importantes como: na França houve o fechamento de clubes femininos, considerados focos de agitação, proibição de reunião com grupos superiores a 3 mulheres na rua. Isto tudo em decorrência da leitura da "Declaração dos direitos da mulher e da cidadã", que foi lida na Constituinte; Napoleão I adenda ao código civil (1807), textos onde coloca a mulher na condição de uma eterna menor, sob tutela do pai ou do marido.

Nas primeiras décadas do século 20 houve obtenção do direito ao voto pelas mulheres. Importantes modificações ocorreram em vários países nesta época. Na Rússia Alexandra Kollontai (1917), teve marcante presença no movimento revolucionário e através de sua atuação houve modificação na legislaçäo vigente: casamento religioso não obrigatório, divórcio concedido quando houvesse consenso no casal, o aborto foi legalizado, coletivização do trabalho doméstico, isto tudo tendo efeito de pouca duração, pois estabeleceram-se outras prioridades com a morte de Lênin, foi aprovada nova lei de casämento que estabelecia pensão para as mulheres divorciadas e Stalin dissolve a organização das mulheres operárias voltando-se a enfatizar o papel da mulher essencialmente, como reprodutora.

Em países socialistas as mulheres obtiveram a igualdade salarial e o pleno acesso a educação, mas como a estrutura da família patriarcal não foi tocada e o autoritarismo predominou, continua a inferioridade.

Nos países capitalistas, a ascensão do fascismo na década de 30 constitui um forte obstáculo para a emancipação feminina.

Na última década houveram várias conquistas no plano legislativo, tais como a aprovação da legalização do aborto em diversos países. Mas, talvez o mais importante tenha sido a noa é a consciência que está se desenvolvendo sobre o papel da emancipação da mulher para a libertação mais ampla da sociedade.

Nesta década, no Brasil, ocorreu um fato importante, devido ao trabalho de mulheres participantes de movimentos feministas que colocavam a importância do voto da mulher, como nos coloca o texto de um manifesto a nação em 1928, assinado por várias mulheres pertencentes a influentes famílias políticas, incluindo a mulher do vice-presidente do Brasil:

"As mulheres, assim como os homens, nascem membros livres $e$ independentes da espécie humana, dotados de faculdades equivalentes e igualmente chamados a exercerem, sem peias, os seus direitos e deveres individuais (. . . . . . . . . A A tacava as falsas crenças na subordinação e recordava a seus oponentes de que aquele que paga impostos e obedece às leis deveria ter uma voz na sua elaboração."

UUNE E. HALMER, 117-18, 1981)

\section{A FAMÍLIA PONTO DETERMINANTE}

Coloca-se em ponto de discussão a fámilia, no momento em que um retrospecto histórico demonstra que foi, através de sistemas familiares, colocado à mulher um papel de inferioridade.

Segundo uma concepção materialista da história a sociedade de uma determinada época está condicionada pelos meios de evolução, onde de um lado encontra-se o trabalho e do outro a família. E a sociedade baseada nos laços sangüíneos explode no choque de classes sociais. No instante em que 
CORADINI, S.R. e colaboradora - A profissional enfermeira frente as influências da evolução histórica da mulher. Rev. Bras. Enf.: RS, 36: 246-254, 1983.

formou-se estas sociedades, a ordem familiar é completamente dominada pela ordem social e na qual ocorrem livremente as lutas de classes que constituem matéria de toda a história até nossos dias.

$\mathrm{Na}$ evolução do casamento desde o estado selvagem há um avanço na liberdade sexual, mais para os homens e restrita para as mulheres dando um caráter de maior peso do que é considerado como uma "honra" para o homem.

Dando continuidade aos diversọs estágios familiares o tipo familiar de matriarcado, onde a mulher quanto o homem eram vistos igualitariamente, teve seu fim, dando origem ao patriarcado.

A medida que as riquezas aumentavam, fortaleciam ao homem a importância familiar, bem como reforçava a idéia de que este patrimônio deveria reverter-se em benefício de seus filhos.

Neste período, não se pode precisar em que etapa, ocorreu a passagem do matriarcado para o patriarcado e exatamente nesta mudança a mulher perde o seu lugar e o homem passa a dominá-la, conforme diz ENGELS em 1974, p. 61:

“... O desmoronamento do direito materno, a grande derrota histórica do sexo feminino e em todo o mundo. $O$ homem apoderou-se também da direção da casa a mulher foi degradada, convertida em servidora, em escrava da luxíria dos homens, em simples instrumento de reprodução. Essa baixa condição da mulher, manifestada sobretudo entre os gregos dos tempos históricos $e$, ainda mais, entre os dos templos clássicos tem sido gradualmente retocada, dissimulada e, em certos lugars até revestida de formas de maior suavidade, mas de maneira alguma suprimida."

A família constituída por monogamia, reflete com grande intensidade o poder do homem sobre a mulher. Na Grécia encontramos homens que lutavam e ao vencedor era oferecida jovens mulheres para caprichos sexuais, os chefes escolhem para si as mais belas pela ordem de categoria. É a existência da escravatura ao lado da monogamia, a presença de mulheres escravas pertencendo de corpo e alma ao homem, que dá um caráter específico de ser monogamia só para a mulher e não para o homem, possuindo ainda hoje este caráter.

A monogamia foi um grande progresso histórico, mas, ao mesmo tempo, ela abre, ao lado da escravatura e da propriedade privada, a época que dura ainda hoje, onde cada passo para a frente é o mesmo tempo um relativo passo atrás, o bem estar e o progresso de uns se realizam através da infelicidade e do recalcamento de outros. É na monogamia que a primeira opressão de classe coincide com a opressão do sexo feminino pelo sexo masculino.

O fato que determina a condição atual da mulher é a sobrevivência obstinada, na civilização nova que se vai esboçando das tradições mais antigas. À mulher são oferecidos cargos, formas de emprego acesso ao estudo mas continua-se a considerar que o casamento é para eles uma carreira das mais honrosas.

\section{ETAPAS DE INFLUÊNCIA}

Ressalta-se aqui de que forma a mulher é levada a ter o posicionamento em que a encontramos atualmente, que condições objetivas, favoreceram e ainda persistem. E é com objetivo de entender como uma fêmea humana á castrada que deve-se considerar as pressões a que é submetida desde o berço.

\section{$3.1 O B e b \hat{e}$}

A criança deve ser civilizada; desde o começo é desencorajada de fazer barulho e exercitar seus pulmões em qualquer ocasião ou lugar em que possa incomodar aos adultos.

A discriminação do menino da menina inicia cedo. Alguns bebês meninas ainda são vestidas de rosa em vez de azul, com roupas frágeis e cheias de babados, e castigadas por rasgá-las ou sujá-las. O cabelo de algumas meninas é encrespado e enfeitado com fitas e é-lhes dito que são uma graça e namoradas do papai.

Perante ao medo de uma não identificação com o seu sexo, lhe são inculcados conceitos de feminilidades sem que a própria menina a perceba.

Cedo uma menina é apresentada ao seu papel doméstico, a mãe lhe ensina habilidades no lar e seu temor da realidade externa é reforçado pelos castigos que sofre por andar na rua por conta própria. Enquanto os meninos estão formando grupos e bandos para explorar ou aterrorizar o distrito. Ela é isolada em casa, escutando histórias de estranhos e malvados, brincando com bonecas è ajudando a mãe. 
CORADINI, S.R. e colaboradora - A profissional enfermeira frente as influências da evolução histórica da mulher. Rev. Bras. Enf.: RS, 36: 246-254, 1983.

\subsection{A menina}

Na medida em que a menina cresce suas atividades são mais severamente limitadas, expansões inocentes são proibidas por que ela esta "grande demais para essas coisas agora". As vezes ela sente como se estivesse sendo jogada numa espécie de vergonhosa condição de mulher, e resiste desesperadamente, a ponto de regredir para um comportamento infantil e destrutivo. E quando se recusa a obedecer todas aquelas exigências que a mãe faz pode ser chamada, pejorativamente de, moleque, como é conhecida.

\subsection{A puberdade}

A menina em crescimento é encorajada a usar seu encanto feminino, a ser mimosa e sedutora, embora ignorando o teatro real em que tais circunstâncias operam. Seus desejos fortes dissipam-se em fantasias passivas enquanto sua conexão com a sexualidade é eficazmente acobertada ou obscurecida, como mostra o texto.

“... Existe a necessidade da criação de esquemas ainda mais repressivos para determinar os limites da sexualidade feminina. E a repressão maior, não é decorrência apenas dos perigos da gravidez; aliás, se tivesse havido a desvinculação do sexo da função reprodutora, há muito tempo se teria sofisticado as práticas eróticas em que se evitaria a ejaculação vaginal, o prazer seria preservado sem os perigos da reprodução fora das regras sociais da família. Na realidade, penso ter sido reforçado o medo da gravidez ao invés de se ter descoberto o modo de se evitar este perigo, e isto como parte de uma postura repressiva máxima, necessária ao enquadramento das mulheres dentro de um padrão suportável para os homens." (FLÁ VIO GIKOVATE, 1980 , p. 60).

Para a mulher a puberdade pode ser considerada como uma espécie de doença natural de origem inorgânica, resultado do condicionamento que mutila a personalidade da mulher criando a personalidade feminina.

Concluindo-se pode-se dizer que decorrentes de todos estes fatos é condicionada a abandonar a autonomia e procurar seu guia. $\mathrm{O}$ número de mulheres que recorre a orientação paternal do psicanalista é indicativo do mesmo fato. As diferenças quanto as optidões e personalidades entre os sexos, são em grande parte resultado de fatores culturais.

\section{A MORAL SEXUAL}

As relações de produção, que durante séculos mantiveram a mulher fechada em casa e submetida ao marido, que a sustentava, são as mesmas que, as arranca as correntes enferrujadas que a aprisionavam, impelem a mulher frágil e inadaptada à luta ao quotidiano, e apartir disto gera independência dos meios de riqueza. Nesta mudança a mulher defronta-se com o problema de se adaptar rapidamente às novas condições da sua existência, e tem que corrigir imediatamente as verdades morais que herdou de suas avós. E dá-se conta de como foi todo Q equipamento moral que recebeu para percorrer os caminhos da vida. As virtudes femininas, passividade, submissão, docı!ra, que lhe foram incutidas durante séculos, tornam-se agora completamente supérfluas, inúteis e prejudiciais. A dura realidade exige outras qualidades das mulheres. Precisa de firmeza, decisão e energia, isto é, aquelas virtudes que eram consideradas como propriedade exclusiva do homem.

Segundo Alecandra Kollontai em 1980, p. 24, diz que:

"As normas morais que regulam a vida sexual do homem não podem ter mais do que duas finalidades, dois objetivos. Primeiro, assegurar à humanidade uma descendência sã, normalmente desenvolvida; contribuir para a seleção natural no interesse da espécie. Segundo, contribuir ao desenvolvimento da psicologia humana, enriquecê-la com sentimentos de solidariedade, de companheirismo, de coletividade."

Entretanto a moral sexual que parece somente servir aos interesses da propriedade, não preenche nenhuma destas duas finalidades. 
CORADINI, S.R. e colaboradora - A profissional enfermeira frente as influências da evolução histórica da mulher. Rev. Bras. Enf.: RS, 36: 246-254, 1983.

As formas atuais de união entre os sexos são contraditórios e complicadas, pois há milhares de anos estamos acostumados a elas e são na verdade resultado da divisão social do trabalho. Entre estas, encontram-se as desiguldades entre o homem e a mulher no prazer sexual e na escolha do parceiro, no esforço e nas realizaçōes intelectuais, e, também, as diferenças entre determinados atributos morais e emocionais, como a dureza e racionalidade "naturais" do homem e a fragilidade e emocionalidade "naturais" da mulher.

\section{A MULHER E O TRABALHO}

Ao se fazer uma análise das condições de trabalho da mulher, encontra-se a mesma muitas vezes em posições de inferioridade recebendo salários menores, que os homens, mesmo quando exercem a mesma função.

As profissões tipicamente femininas, mesmo as que exigem um reparo intelectual (magistério, enfermagem, assistente social) recebem salários inferiores à média. No caso das profissões que não exijam um preparo técnico e intelectual, como empregada doméstica faxineira, lavadeira, cozinheira, a maioria recebe menos de meio salário mínimo e ainda trabalham mais de 8 horas por dia.

À mulher foi relegado o trabalho doméstico, ou também ocorre que quando trabalha fora de casa, ao chegar em casa, precisa realizar todas as tarefas domésticas, levando portanto uma dupla jornada de trabalho.

Mesmo quando a mulher trabalha fora, seu ofício na maioria das vezes é o de servir os homens. A espécie mais aberta de servilidade é praticada pelas secretárias, de cuja função faz proteger os egos de seus patrões e mesmo encobrir-lhe os erros.

GERMAIN GREER em 1974 p. 155, ern seu livro a Mulher eunuco, reproduz um artigo do Sunday Times, onde coloca instruções a que a perfeita secretária deve seguir:

“1. Sempre use um desodorante, você nãoé aquela garota entre mil que não precisa de um.

2. Aprenda como fazer bom chá e café.

3. Não dê à mamãe, namorado, marido ou titia o número do telefone do

escritório.

4. Use o toalete para aplicar baton, cílios postiços, pintar unhas e mudar meius.

5. Não coloque as más notícias no alto da correspondência que chega.

6. Parę̧a sempre bela, mas não provocadora."

Ao se olhar em uma coluna de classificados encontra-se atributos, qualidades como: ser atraente, boa, organizada, de temperamento calmo, viva, inteligente, cheia de tato, eficiente, brilhante, que devem estai presentes em uma mulher secretária.

Um fenônemo deprimente no padrão de trabalho das mulheres e a condição das enfermeiras. A enfermeira iniciou quando Florence Nightingale empregou as filhas ociosas da classe média vitoriana num trabalho de misericórdia que afastava delas a malevolência, de maneira que as mulheres ricas ainda trabalham para a Cruz Vermelha. Enfermagem e Magistério foram por muito tempo as profissões femininas mais populares, na verdade, quase se pode dizer, as únicas profissões femininas.

Ao completar sua formação, uma enfermeira, é lançada ao mercado de trabalho onde é exigido um comportamento de obediência. A desculpa para tudo isto é o paciente, mas é o paciente que sofre nas mãos de enfermeiras cansadas, ressentidas e maltratadas.

Existe uma infinidade de profissões onde encontraremos muitas mulheres, $\epsilon$ mesmo em atividades onde a mulher domina, os postos mais importantes são ocupados por homens. As aeromoças são invejadas por seu cargo mas infelizmente não passam de garçonetes glorificadas, e com freqüência presididas por um comissário.

Buscando realizações acadêmicas assexuais, uma moça se defronta com um inimigo incansável: sua família. As recriminaçōes constantes, as lamentaçōes sobre o que está perdendo no referente as coisas que divertem as outras, como namorar e roupas bonitas, as advertências de que jogará o esforço quando casar, toda esta insistência diminui gradativamente dia após dia.

\subsection{A mulher e a CLT}

Integra a consolidação das leis do trabalho um capítulo especial que estabelece as normas de proteção ao trabalho da mulher junto a ela, uma reduzida legislação complementar compõe o elenco dos direitos da mulher no trabalho. 
CORADINI, S.R. e colaboradora - A profissional enfermeira frente as influências da evolução histórica da mulher. Rev. Bras. Enf.: RS, 36: 246-254, 1983.

O artigo 165, item 3 da constituição brasileira proíbe que haja diferença de salário por um mesmo trabalho, por motivo de sexo, nacionalidade ou estado civil. Já o artigo 377 da CLT determina que a adoção de medidas de proteção ao trabalho das mulheres é considerado de ordemı pública, não justificando, em hipótese alguma, a redução de salários. Não obstante tais disposições legais, a Comissão Parlamentar de Inquérito criada pelo Congresso em 1977 para examinar a situação da mulher na sociedade brasileira conclui que é indisfarçável a existência da discriminação contra a mulher em quase todos os setores da atividade humana que compõem o mecanismo da sociedade brasileira. Pode também constatar que a discriminação ao trabalho da mulher existe de fato, evidenciando-se nos aspectos salarial e de acesso às carreiras. Sendo que em seu relatório final, propôs entre outras a revisão de toda a legislação protetora do trabalho feminino, para que cada uma das normas depois de analisadas, seja estendida a todos os trabalhadores ou eliminada para todos eles.

No Brasil, com relação a maternidade, a história mostra uma certa garantia para a mulher gestante.

Já a questão das creches, historicamente, nunca foi encarada com seriedade, seja pela legislação trabalhista, seja pela previdenciária.

Dentre outras, pode-se dizer que a mulher trabalhadora é, hoje, a grande vítima não só de uma exploração decorrente da acumulação capitalista selvagem característica do modelo econòmico brasileiro, como também de umá opressão a nível cultural, de raízes muito profundas, limitadoras de sua função social. A sociedade não oferece uma infra-estrutura capaz de assegurar sua entrada no mercado de trabalho em igualdade de condições com o homem.

\section{O PERFIL ATUAL DA PROFISSIONAL ENFERMEIRA}

A proposta desta análise acontece no momento em que é comprovada a clara interferência, na história evolutiva da Enfermagem, da história de opressão e subserviência da mulher no contexto geral da sociedade.

Inicialmente vale destacar que para uma análise mais profunda da história serão enfatizados aspectos da Enfermagem de maior importância na contribuição para o estudo proposto.

A história da Enfermagem divide-se em período pré-cristão, período da Unidade Cristã, período crítico da Enfermagem, precursores da Enfermagem modernas, período Florence Nightingale e a Enfermagem no Brasil.

No período pré-Cristão onde os sentimentos de humanidade conduziam os indivíduos a servir o outro, pode-se pressupor a mãe como participante ativa , dos cuidados de saúde na família, a partir disto, podendo ser considerado como primeira enfermeira da família.

Os conhecimentos de enfermagem estão ao redor de assuntos médicos, sociais e religiosos.

Na Unidade Cristã, o Cristianismc se constituiria na maior e mais profunda revolução social.

Através deste período onde exaltou-se os princípios Cristãos e as pessoas foram acometidas de grande dedicação e bondade as mulheres nas pessoas das mais distintas damas da sociedade vigente, e religiosas agruparam-se e começaram a dar assistência aos mais pobres.

Desta fase destaca-se a figura feminina de Santa Hildegarda que conseguiu curas notáveis, sendo que seus conhecimentos médicos sobrepujaram aos dos homens mais notáveis de seu tempo, também Catarina de Siena constituiu-se uma figura admirável no progresso da Enferrnagem, usava lâmpada para ordenar doentes abandonados pelas ruas escuras de Siena.

O período crítico da Enfermagem mostra o quanto a decadência cristã influiu e colocou pessoas sem capacidade alguma para dar assistência aos enfermos.

Os pretensos "enfermeiros" desta época eram pessoas que deixavam os doentes no abandono, morrendo e lhes extorquiam gorjetas.

Através do concílio de Trento definiu-se formas de uma melhor assistëncia, que serviu como porito de partida para numerosas organizações religiosas dedicadas a Enfermagem.

No período dos precursores da enfermagem moderna, surge São Vicente, que inconformado com os problemas sociais vigentes na época, reúne senhoras da burguesia e forma grupos de assistência.

No período denominado Florence Nightingale, predomina a marcante presença da Enfermeira Florence Nightingale.

Teve participação importante em 1854 na guerra da criméia, onde com a ajuda de 38 voluntários partiu para os lugares oncle se encontravam os feridos. Organizou e dirigiu os trabalhos de enfermagem aos enfermos, diminuindo a taxa de mortalidade entre os feridos que até então era altíssimo. 
CORADINI, S.R. e colaboradora - A profissional enfermeira frente as influências da evolução histórica da mulher. Rev. Bras. Enf.: RS, 36: 246-254, 1983.

No Brasil a enfermagem, teve como seu iniciador os jesuítas. A primeira voluntária de enfermagem no Brasil foi Francisca de Sande. Nesta época a medicina sofreu um grande impulso o que não ocorreu com a enfermagem.

As funções de enfermeiras eram relegadas ao plano doméstico ou religioso, sem nenhum caráter técnico ou científico, e não era cogitado preparo de profissionais.

$\mathrm{Na}$ época do Império no Brasil baseado em uma concepção dos indivíduos em geral e os médicos, de que enfermagem necessitava de bases muito rudimentares, fez com que poucas pessoas se destacassem neste campo, como Ana Neri, que foi um nome importante nesta época, atuando na guerra do Brasil com o Paraguai, merecendo por este trabalho medalhas de reconhecimento.

A Enfermagem moderna no Brasil, teve início nos idos de 1923, com criação da Escola de Enfermagem Ana Neri no Rio de Janeiro, graças a iniciativa dos sanitaristas da época liderados por Carlos Chagas.

Após um relato histórico, cabe fazer um análise profunda das interferências que se salientam no decorrer da história da mulher e que reforçam e até explicam o porque da situação atual da profissional Enfermeira.

ALBERTO COSTA, em 1947, p. 22, destaca qualidades que seriam importantes encontrar no Enfermeiro como: "Ser enfermeira é ter de viver pelos outros, em prejuízo de si próprio", enfatizando um princípio de religiosidade que acompanha desde o início, a profissional através das religiosas, que tiveram papel preponderante na enfermagem, não desmerecendo a sua importância através desta análise.

O espírito de caridade, paciência, abnegação e outros, não foram por acaso que apareceram, são provenientes de toda uma estrutura religiosa que acompanha o profissional, infelizmente até nossos dias.

O paciente espera um comportamento abnegado pois muitas vezes liga a imagem de enfermeira a mãe e como nos mostra CÉLIA ALMEIDA FERREIRA em 1973, p. 119 que:

"Estes traços psicológicos sugerem envolvimento afetivo, aliás esperando das enfermeiras religiosas: amor ao próximo."

Reforçando o espírito vigente naquela época, ALBERTO DA COSTA 1947, p. 24-5, diz que é importante o:

"O enfermeiro ser leal, obediente e respeitador, obrigaçōes estas que todos nós devemos a quem ocupa, na escala social, um lugar superior ao nosso (...... Se o médico ou qualquer superior se aproxima o enfermeiro levanta-se
para lhe fornecer quaisquer dados ou informaçóes de que necessite segue o médico, quando este vai fazer a visita às enfermarias toma apontamentos sobre as ordens que recebe, relativas a cada doente; não se preocupa nem se enfastia com o trabalho que estas ordens levarão a cumprir; e de novo o acompanha até a porta."

MIRADOR, no dicionário brasileiro de Língua Portuguesa em 1975, o. 672, diz que:

E Enfermeiro, s.m. (enfermo + eiro). Aquele que trata dos doentes nos hospitais ou no domicilio, administrador geral de alguns hospitais.

Enfermeira, s.f. (feminino de enfermeiro). Mulher instruida e habilitada para cuidar de enfermos e feridos sob a supervisão de um médico."

Mostra este autor a clara dominação do homem a mulher, a meiguice, docilidade, sensibilidade e outras qualidades que foram inculcadas na mulher desde o seu nascimento também são repassadas para a profissional-enfermeira, diferenciando das qualidades e atividades masculinas (enfermeiro).

Outro esterótipo é quanto a moralidade como relata CÉLIA ALMEIDA FERREIRA, 1973, p. 66, apartir de trabalhos realizados com com colegiais em Ribeirão Preto.

“... Sabe os aspectos morais da profissão: profissão malvista, que pode corromper os sentimentos e qualidades morais, pelo conceito de baixa moralidade que domina a profissão." 
CORADINI, S.R. e colaboradora - A profissional enfermeira frente as influências da evolução histórica da mulher. Rev. Bras. Enf.: RS, 36: 246-254, 1983.

Parece que toda a conjuntura formada ao poder da enfermeira, que traz hoje discussões e reformulações esta centrada no verdadeiro papel que ela exerce dentro de suas atividades e como ela é vista tanto pela sociedade como para os elementos da equipe de saúde, que trabalha mais diretamente.

A enfermeira ao considerar que certas tarefas que lhe eram atribuídas, não condiziam com o seu status profissional, passou a exercer funções mais administrativas, o que proporcionou uma elevação do seu ego.

Diante deste fato, passou ela a não mais atender diretamente o paciente, somente delegando funções aos outros elementos da equipe de enfermagem.

Nesta escala de modificações revê a Enfermeira, hoje, seu trabalho para uma assistência ao paciente, mais científica e mais desburocratizada.

As enfermeiras, como mulheres, desempenhando papéis femininos entram na situação de trabalho já com posição definida de submissão em relação aos grupos masculinos com os quais interagem.

Reforçando a motivação segregativa, existem hospitais onde os homens (médicos), mantém ideologias discriminatórias quanto à profissionalização da mulher. Eles tendem a conservação em relação as enfermeiras atitudes de domínio e exigências de submissão. Por outro lado, solicitam delas, eficiência e iniciativa. Esta ambivalência coloca também as enfermeiras em posição ambígua frente aos médicos; objetos catéticos dos quais não conseguem se libertar, porque suas atividades estão diretamente ligadas na recuperação do paciente.

A apresentação do perfil da Enfermeira pode parecer um tanto negativista, mas uma perspectiva nova delinha-se no instante em que, é feita uma análise, constatada a realidade e apartir disto procura-se formas de solução.

Um novo caminho já está colocado às enfermeiras, num momento em que a própria mulher está se voltando para suas origens e reavaliando padrões que lhe foram pré-estabelecidos. E é nesta etapa que deve a enfermeira unir-se as outras mulheres e discutir, descobrir novas formas de interferência tanto em seu campo profissional como na sociedade, mostrando todo o potencial que se encontra encoberto, mas que pouco a pouco emerge da névoa de opressão a que estava acorrentada.

Os chamados "anjos brancos" não mais andarão nos corredores, silenciosos como se estivessem sobre nuvens, estarão sim em diversos setores da sociedade, participando, opinando, juntamente com toda a população, reivindicando por melhores condições de vida.

\section{CONCLUSÃO}

Diante destes fatos mostrados constata-se realmente que existe uma situação muito característica, na enfermeira, que sofreu influências da história da mulher.

Conclui-se que a enfermagem seria uma das profissões que permitem, nesta época de transição, maior possibilidade de emancipação feminina e conseqüente participação na população economicamente ativa. Esta profissionalização da mulher, entretanto conserva características do tratamento discriminativo em relação aos sexos, quando se afirma como profissão predominantemente feminina e "subordinada" a uma profissão predominantemente masculina.

Coloca-se como ponto inicial de opressão o próprio modelo familiar vigente em nossa sociedade, que contribui grandemente para a própria situação.

Partindo duma análise familiar, são considerado dados os passos importantes da infância até a adolescência e comprova-se o quanto são influentes estas marcas, no instante em que condicionam a mulher a possuir determinados comportamentos.

A moral sexual exerceu e ainda exerce importante pressão sobre a mulher e define-se que os indivíduos só conseguirão de plenitude quando souberem se relacionar sem que domine ou seja dominado.

Os esteriótipos formados em torno da enfermeira, são muito fortes e cabe as profissionais reverter este processo através, primeiramente de um maior conhecimento de seus condicionamentos e após isto aí concomitante uma verdadeira luta de igualdade profissional, como qualquer outro indivíduo da sociedade.

E é através de discussão, em grupos de mulheres organizadas que vai se dar este aprendizado, pois é lá que com outras mulheres, poderia se analisar toda as opressões que se submeteram e apartir daí alcançar, na sociedade, o lugar que todo o indivíduo deve ter.

Cabe a enfermeira dentro de seu campo de trabalho processar formas de atuação condizentes com o seu grau de instrução, pois se não procurar formas alternativas e não começar a participar ativamente dos destinos da civilização corre o risco de acabar em um museu, como espécie obsoleta. Com um título embaixo dizendo: "Extinta por ser inútil". 
CORADINI, S.R. e colaboradora - A profissional enfermeira frente as influências da evolução histórica da mulher. Rev. Bras. Enf.: RS, 36: 246-254, 1983.

\section{SUMMARY}

This bibliographical study shows the origins of woman's historical opression as much as the factors the influence her as abeing and as a professional worker. It analyzes thet repercussion of social, political and economical factors establishing a relationshi with nursing that is formed in its majority by women. At end of this study we show the stages of woman's evolution in nursing, her historical professional subjection. It proposes as opcions:

$1{ }^{\circ}$ To get conscious of her situation;

2. Possible ways of actuation as a professional worker;

3. And, nowadays, the legalization of her work and the nursing process as a means to acquire professional autonomy.

\section{REFERÊNCIAS BIBLIOGRÁFICAS}

1. ARCHER, Sarah Ellen. et. alli, Enfermeria de salud comunitária. Organização Panamericana de la Salud, 1977, Colombia.

2. BERLINGER, Giovanni. A mulher e a saúde. Oboré, São Paulo, 1978.

3. BEAUVAIR. Simone de. O segundo sexo. Rio de Janeiro, Nova Fronteira, 1980.

4. COSTA, Alberto. Enfermagem, 4. Edição. Cambra, 1947.

5. COSVOLKI, Genoefa. et alli, Desvio das funçōes e atribuiçōes do enfermeiro em Santa Maria-RS. Rio Grande do Sul, 1976.

6. CUNHA, Maria Carneiro da. A mais longa das lutas. Jornal o Movimento, São Paulo, 1981.

7. ENGELS, Friedrich. A origem da família, da propriedade privada e do estado. 3. Edição. Rio de Janeiro, Civilização brasileira, 1974.

8. GREER, Germaine. A mulher eunuco. São Paulo, Círculo do Livro, 1974.

9. GIKOVATE, Flávio. Falando de amor e dificuldades no amor. São Paulo. Círculo do Livro, 1974.

10. GIKOVATE, Flávio. O instinto sexual. São Paulo, MG Editores Associados, 1980.

11. HALMER, June E. A mulher brasileira e suas lutas sociais e Políticas 1850-1937. São Paulo, Brasiliense, 1970.

12. KOLLONTAI, Alexandra. A nova mulher e a moral sexual. 4. Edição. São Paulo, Global Editora e Distribuidora, 1980.

13. MASTER \& JOHNSON. O vínculo do prazer. São Paulo, Círculo do Livro, 1975.

14. MARX et alli, Sobre a mulker. Global Editora e distribuidora. 2a Edição. São Paulo, 1980.

15. MACHEL, Saomora. et alli. A libertação da mulher. 2a Edição, São Paulo, Global, 1980.

15. PAIXÃO, Waleska. História de enfermagem. 4. Edição. Rio de Janeiro, 1957.

17. PASSOLO, Dr. Adolpho. Curso de enfermeiras. 7a Edição. Freitas Bastos, 1948.

18. RANGEL, Dr. Mário. Curso de enfermeiras. Rio de Janeiro, Universo, 1957.

19. SANTOS, Célia Almeida Ferreira. A enfermagem como profissão. São Paulo, Editora da Universidade de São Paulo, 1973.

20. SILVEIRA, Enio. Mulher hoje. Rio de Janeiro, Civilização brasileira, 1980.

21. SHEEHY, Gail, Passagens. São Paulo, Círculo do livro, 1976.

22. STUDART, Heloneida. Mulher objeto de cama e mesa. 6. Edição. Rio de Janeiro, Vozes, 1974

23. WHITE, Dorothy T. et alli. Fundamentos de enfermagem. São Paulo, Editora Pedagógica e Universitária, 1976.

24. LISA. Grande Dicionário da Língua Portuguesa; Rio de Janeiro. Livros inadiantes, 1972.

25. MIRADOR INTERNACIONAL. Dicionário Brasileiro da Língua Portuguesa, 1975, São Paulo.

26. ENFERMAGEM brasileira em defesa dos seus direitos. COFEM. Rio de Janeiro, 1980.

27. INICIAMENTO de Metodologia do processo de enfermagem. ABEn Seção Guanabăra.

28. REVISTA QUERO-QUERO. Órgão Oficial da UFSM, n. 30, 1981. 